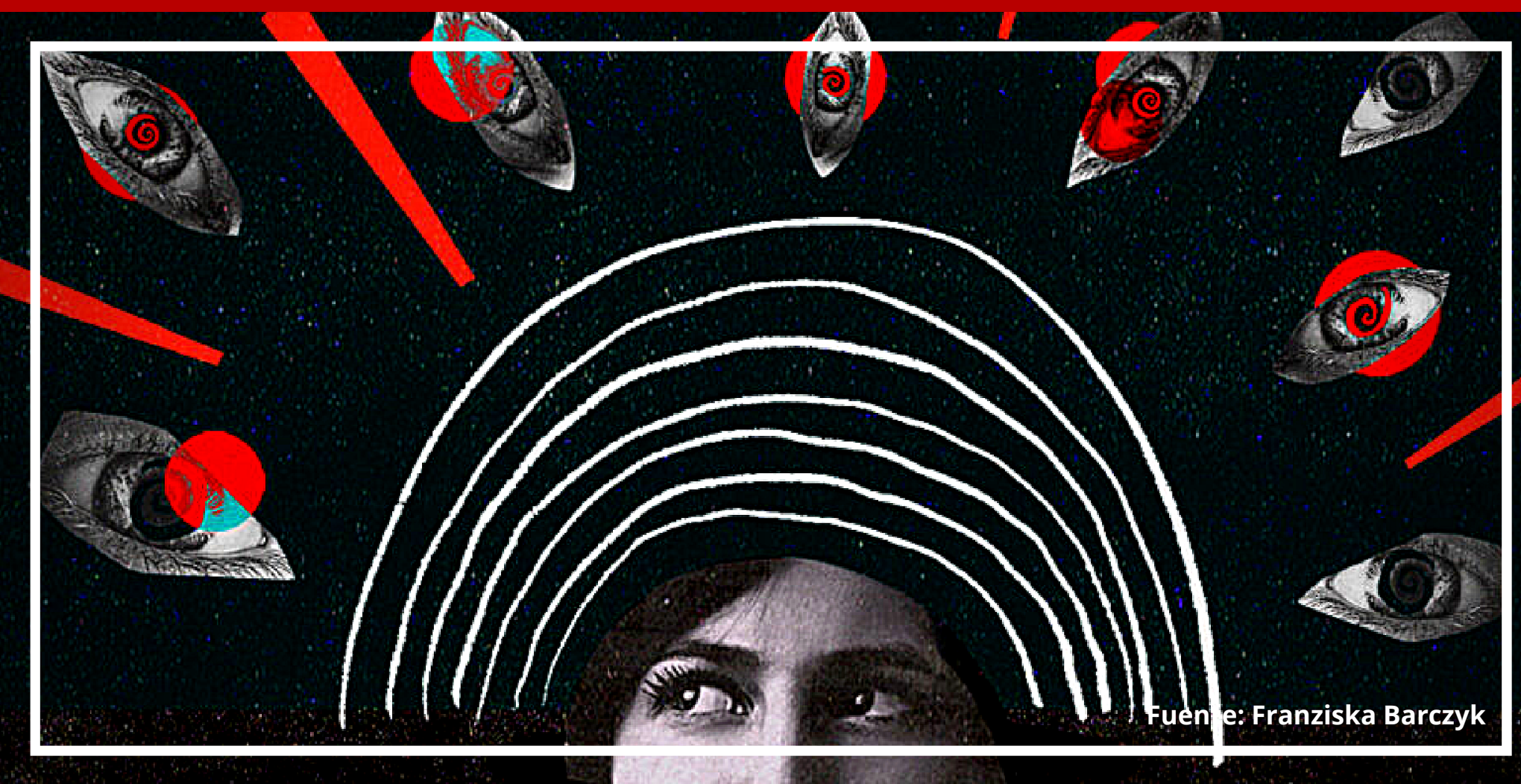

Los argumentos conspirativos en las redes sociales en el contexto de la pandemia

\author{
doi: $10.52749 /$ rh.v1i1.3
}

\title{
FREDDY JAIMES
}

(iD https://orcid.org/0000-0002-7128-6830

Licenciado en Psicología por la Universidad San Martín de Porres, Magíster en Investigación y Docencia Universitaria y Doctor en Psicología por la Universidad Inca Garcilaso de la Vega. Director de la revista Humanista de la Sociedad Secular Humanista del Perú.

f.jaimes@ssh.org.pe

\section{DORISS VERA}

\section{iD https://orcid.org/0000-0003-3955-6316}

Egresada de las carreras de Literatura y de Educación de la Universidad Nacional Mayor de San Marcos. Miembro de la Sociedad Secular Humanista del Perú.

$\checkmark$

razverb@gmail.com

Resumen. En el presente trabajo se parte del hecho de que las teorías conspirativas se han vuelto comunes en las redes sociales durante la pandemia, y que estas se transmiten a través de argumentos. Se demostrará en tres ejemplos que dichos argumentos no son válidos desde la perspectiva formal o en cuanto a su semántica.

Palabras clave: argumentación, entimemas, falacias, pandemia, redes sociales.

Cómo citar este artículo:

Jaimes, F., \& Vera, D. (2021). Los argumentos conspirativos en las redes sociales en el contexto de la pandemia. Revista Humanista, 1(1), 16-22. https://doi.org/10.52749/rh.vlil.3

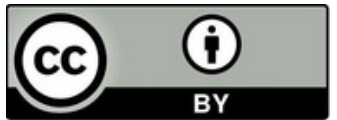




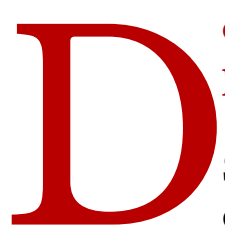

escripción de la realidad problemática

$\mathrm{Si}$ bien es cierto que la comunicación es vital en la vida social, también lo es el que las faltas lógicas y a la verdad cometidas durante el proceso de la comunicación ayudan a construir narrativas coherentes y funcionales para ciertos grupos (el racismo para los nazis, el daño de las vacunas para los antivacunas, el patriarcado para el feminismo). Sin embargo, pese a su funcionalidad, cuando se las extrapola a una sociedad impiden acceder al conocimiento científico y así crean caos y dificultan las relaciones sociales. En contextos críticos, como el de una pandemia, pueden ser responsables de la desobediencia civil a las medidas preventivas, lo que conllevaría al aumento de contagios e incluso de muertes.

Durante la pandemia del coronavirus, las redes se han saturado de comentarios sobre la existencia misma del virus y de la pandemia, sus orígenes, el papel de las farmacéuticas, la eficacia de las vacunas y las posibles curas. Muchos de estos argumentos están estructurados de manera que la conclusión se deriva de las premisas deductiva $o$ inductivamente; es decir, son argumentos válidos. No obstante, frecuentemente sus premisas y sus conclusiones no se condicen con la realidad, sino que son postulados de origen conspirativo.

Así como las pseudociencias utilizan términos científicos para dar apariencia de verdad a sus creencias, las teorías conspirativas podrían utilizar la formalización argumentativa para validar sus conclusiones. Esto es posible porque poseen una narrativa coherente, en tanto que sus ideas mantienen una coherencia interna que vuelve verosímil su relato.

Por ejemplo:

1.Los poderosos quieren controlarnos.

2.Los poderosos manejan las farmacéuticas.

3.(de 1 y 2 ) Los poderosos pueden utilizar las farmacéuticas para controlarnos.

4.Los chips se pueden utilizar para controlar mentalmente a las personas.

5.Las farmacéuticas han logrado insertar chips en las vacunas.

6.(de 3, 4 y 5) Los poderosos utilizan las vacunas para insertarnos chips que nos controlarán.
Las opiniones y los debates, por tanto, resultan improductivos y llevan a decisiones erróneas no porque necesariamente contengan falacias, sino porque parten de premisas coherentes entre sí, pero inconsistentes con la realidad. Gran parte de la dificultad de los debates -así como del uso de argumentos falaces- parece deberse al rechazo a la ciencia de ciertos grupos. Se verifica, por tanto, un rechazo también al razonamiento lógico, lo que conlleva a la "licencia" del uso de argumentos no rigurosos ni sometidos a criterios lógicos o de verificación empírica.

Así pues, cuando un médico o una persona científicamente informada debate con un defensor de una teoría conspirativa, será prácticamente imposible que pueda convencerle con pruebas y argumentos científicos, ya que estos serán desestimados de antemano al no ser congruentes con su narrativa conspirativa. De la misma manera, cuando las autoridades estatales toman medidas para contrarrestar o paliar los efectos de la pandemia, cierta parte de la población suele desconfiar de ellas, pues no son coherentes con la narrativa conspirativa en la que creen, por lo que optan por contravenir directamente las medidas.

Por tanto, los efectos nocivos de las faltas a la lógica y a la verdad en los discursos, lejos de restringirse a problemas lógicos o semánticos, inciden directamente en la realidad y en el futuro de poblaciones numerosas. Conocer cómo se articulan la narrativa conspirativa y sus presupuestos -que suelen estar implícitos en los debates de las redes sociales- podría ayudar a psicólogos, sociólogos, educadores e incluso autoridades estatales a interpretar correctamente las opiniones y diseñar planes estratégicos para contrarrestar sus efectos más perjudiciales, especialmente en situaciones críticas como una pandemia.

\section{Teorías Conspirativas}

Toda teoría implica un cuerpo estructurado de ideas que son coherentes entre sí. Esto también se aplica a las teorías conspirativas. Según Hernáiz (2009), las "teorías conspirativas" son "aquellas que consideran que todo evento social es la consecuencia de la maquinación de una fuerza superior y, a menudo, secreta". Suele utilizarse esta expresión para aludir a un sistema de ideas que presumen la existencia de un gru- 
po de poder con la capacidad para controlar el mundo según su conveniencia, de manera que quienes no pertenecen a ese grupo carecen de libertad real, aunque crean que la tienen. Sin embargo, también dentro de este sistema, se propone la existencia de un grupo de personas "iluminadas" que han logrado darse cuenta del "real funcionamiento del mundo" y sienten la obligación moral de comunicar su conocimiento para enfrentar al grupo de poder.

Las teorías conspirativas sistematizan sus ideas con una lógica interna sujeta a la causalidad, la cual constituye su fortaleza más importante. Sin embargo, por más coherentes que estas ideas sean entre sí, no pueden contrastarse de ningún modo. Las teorías conspirativas vinculadas con la pandemia que se tratarán en el presente artículo giran en torno a las causas y los efectos de la pandemia.

En líneas generales, los argumentadores conspirativos aseguran que hay un sistema poderoso - humano o suprahumano- cuyo objetivo es mantenerse en el poder a través de estratagemas que inducen al miedo y orillan a la población a dejarse manipular por el terror para entregar su libertad de pensamiento y acción a los poderosos que dominan tal sistema. La pérdida de esta libertad se consumará, por ejemplo, por medio de las vacunas -con sustancias o chips- modificadas gracias al conocimiento científico.

Los silogismos usados por los conspirativos suelen carecer del enunciado antecedente o del enunciado consecuente. Así pues, pueden catalogarse como entimemas, entendidos en el sentido más general de "silogismos incompletos". Las falacias son también comunes en los argumentos conspirativos. Para efectos del presente trabajo, se utilizará el concepto de Bordes de falacia: "argumento racionalmente no convincente, es decir, aunque puede ser válido, contiene un error inferencial por violar uno o más criterios de buena argumentación [1] (p. 137).

Para analizar los silogismos conspirativos se identificará los entimemas utilizados y se propondrá el enunciado elidido que completaría el silogismo.

Análisis de argumentos conspirativos CASO 1:La República 28 de agosto de 2020. Orlando Arapa (congresista peruano).
"Estos días hemos recibido muchas llamadas telefónicas de las provincias de Azángaro, El Collao, San Román, Moho, nos han llamado nuestros hermanos y nos han dicho que, probablemente, estarían circulando avionetas y drones y estarían esparciendo el coronavirus".

"Cuando en Tacna sobrevolaban avionetas, miren lo que pasaba, incrementaba la cantidad de fallecidos".

"Hermanos laven las cosas, usen lejía, detergente, para que si fuera así, podemos contrarrestar esto. Es lamentablemente el sistema y el poder en el que vivimos, pueda hacer de todo (...)" (sic).

\section{ESTANDARIZACIÓN DEL ARGUMENTO ENUNCIADO}

\section{Probablemente en Tacna sobrevuelan avionetas y drones.}

2. Las avionetas y drones esparcirían el coronavirus.

3. (de 1 y 2) En Tacna se incrementa la cantidad de fallecidos por coronavirus cuando la sobrevuelan avionetas y drones.

-En el aspecto formal, el silogismo presenta dos premisas a las que el enunciador atribuye grado de validez probable, pero la conclusión es una afirmación generalizadora, por ello, solo es válido inductivamente, mas no deductivamente.

-En el aspecto semántico-pragmático, las premisas están sujetas a un sistema de creencias conspirativo en el que hay alguien que ordena y permite que aviones y drones sobrevuelen Tacna con fines asesinos. Hay, por tanto, un entimema, pero este contiene una información que no se ajusta a los hechos.

-El contenido elidido de este entimema se resuelve líneas después cuando afirma que hay "un sistema, un poder" capaz de "hacer de todo".

-Dado que "hacer de todo" se ha manifestado en Tacna como "esparcir coronavirus", se concluye 
que el sistema tiene el poder de causar daño y desea hacerlo.

-El grado de probabilidad que se otorga a las premisas contrasta con la afirmación tajante del segundo párrafo: "Cuando en Tacna sobrevolaban avionetas, miren lo que pasaba, incrementaba la cantidad de fallecidos". Es decir, el segundo párrafo elimina la probabilidad y da validez de verdad tanto al sobrevuelo como a la acción de esparcir coronavirus.

-Si se incluye en el entimema la información elidida, el silogismo sería:

ESTANDARIZACIÓN DEL ARGUMENTO CON INCLUSIÓN DEL ENTIMEMA

\section{Hay un sistema poderoso.}

2. El sistema puede hacer daño.

3. El sistema quiere hacer daño.

4. El sistema quiere incrementar la cantidad de muertes en Tacna

5. En Tacna sobrevuelan avionetas y drones por orden del sistema.

6. El sistema ordena a las avionetas y a los drones esparcir el coronavirus.

7. Las avionetas y los drones esparcen el coronavirus

8. (de 1 a 7) Por orden del sistema, en Tacna se incrementa la cantidad de fallecidos por coronavirus cuando la sobrevuelan avionetas y drones

-Pese a que la conclusión obtenida se deriva de las premisas, sigue siendo errónea en función de su semántica, pues presupone que la muerte por coronavirus sucede inmediatamente después del contagio. No obstante, esta presunción no se ubica en los parámetros de la teoría conspirativa, sino en el de la carencia de información científica.
CASO 2:La República 19 de abril de 2020. Marat Safin (exjugador de tenis ruso)

"Creo que no todo es como se dice, es una situación preparada. Pero la gente se cree todo, en las historias de terror en la televisión. No se va a acabar la civilización, pero simplemente pronto iremos con el chip implantado"

"En 2015, Bill Gates dijo que tendremos una epidemia, luego una pandemia y que nuestro próximo enemigo era un virus, no una guerra nuclear. Simplemente lo sabía y todos se estaban preparando"

"En el Foro Económico Mundial de Davos se efectuaron simulaciones dos semanas antes de que se conociera el [corona]virus en el mundo. Entonces el 5G ¿Por qué comienza? Luego se introducirán los nanochips. Todo va a eso. Mira lo que está pasando a tu alrededor. La gente está en pánico, todo está como debería"

"Creo que hay hombres más poderosos que todos estos líderes. Tipos que realmente manejan el dinero, dueños del mundo que pueden cambiar las cosas en el sentido que quieran"

ESTANDARIZAGIÓN DEL ARGUMENTO ENUNCIADO

1.En 2015 Bill Gates dijo que tendríamos una epidemia y luego una pandemia.

2. En 2015 Bill Gates dijo que nuestro próximo enemigo sería un virus, no una guerra nuclear.

3. En el Foro Económico Mundial de Davos se efectuaron simulaciones dos semanas antes de que se conociera el [corona]virus en el mundo.

4. (de 1, 2 y 3): La pandemia es una situación preparada.

5. Los dueños del mundo pueden cambiar las cosas en el sentido que quieran.

6. (de 4, 5 y 6): Pronto nos implantarán chips. 
-En el aspecto formal, la primera conclusión no se deduce de las premisas, pues se confunde la correlación con la causalidad. La segunda conclusión tampoco se deriva de las premisas, pues estas no contienen alguna idea vinculada con los chips.

-En el aspecto semántico-pragmático, las premisas están sujetas a un sistema de creencias conspirativo en el que hay un grupo que produce una pandemia y se prepara con el fin de utilizarla para controlarnos a través de chips. Hay, por tanto, un entimema.

-El contenido elidido de este entimema se resuelve en el primer párrafo ("no todo es como se dice, es una situación preparada. Pero la gente se cree todo, en las historias de terror en la televisión") y en el último ("hay hombres más poderosos que todos estos líderes. Tipos que realmente manejan el dinero, dueños del mundo que pueden cambiar las cosas en el sentido que quieran").

-A partir de estas afirmaciones, se comprende que en esta teoría conspirativa el sistema poderoso puede llevar a cabo sus planes porque infunde terror en las personas a través de los medios de comunicación. El terror ocasiona que las personas se vuelvan dóciles y crean en la necesidad de una vacuna, dentro de la cual estará el chip que los controlará.

-Si se incluye en el entimema la información elidida, el silogismo sería:

ESTANDARIZAGIÓN DEL ARGUMENTO CON INCLUSIÓN DEL ENTIMEMA

1.Hay un sistema poderoso.

2. El sistema puede hacer daño.

3. En 2015 Bill Gates dijo que tendríamos una epidemia y luego una pandemia.

4. En 2015 Bill Gates dijo que nuestro próximo enemigo sería un virus, no una guerra nuclear.

5. Bill Gates es parte del sistema poderoso.
6. (de 1 a 5): El sistema planea una pandemia.

7. Los dueños del mundo pueden cambiar las cosas en el sentido que quieran.

8. Con los chips se puede controlar a las personas.

9. (de 6 a 8): El sistema quiere controlar a la población a través de chips.

10. El sistema utiliza medios de comunicación para infundir miedo en la población.

11. (de 9 y 10): El miedo llevará a la población a dejarse implantar chips y a ser controlada por el sistema.

-Pese a que la narrativa presente en el silogismo tiene coherencia interna, sigue siendo errónea en función de su semántica, pues presupone que la pandemia no afecta negativamente a las personas con más poder en el planeta. También asume que todos los medios se subordinan a los intereses de un grupo.

CASO 3:La Vanguardia, 15 de junio de 2020. Antonio Cañizares (cardenal arzobispo de Valencia)

"El demonio existe en plena pandemia, intentando llevar a cabo investigaciones para vacunas y para curaciones. Nos encontramos con la dolorosísima noticia de que una de las vacunas se fabrica a base de células de fetos abortados"

"Y eso es ir en contra del hombre, eso es despreciar al hombre mismo, primero se le mata con el aborto y después se le manipula para... qué bueno, mira qué bien... ya tenemos una vacuna. No señor, tenemos una desgracia más, obra del diablo. Eso es lo que quiere el diablo", afirmó Cañizares durante su homilía" 
ESTANDARIZACIÓN DEL ARGUMENTO ENUNCIADO

1.El demonio realiza investigaciones para encontrar una vacuna.

2. El demonio utiliza abortos para investigar sobre la vacuna.

3. (de 1 y 2): El demonio está presente en la pandemia y la vacuna no es buena para la humanidad.

-En el aspecto formal, se trata de un argumento circular, por lo que es inválido.

-En el aspecto semántico-pragmático, las premisas están sujetas a un sistema de creencias conspirativo en el que hay un ser sobrenatural demoniaco que utiliza fetos abortados para encontrar una vacuna. Si el aborto ya de por sí es malo, el uso de los fetos abortados para producir una vacuna es una estratagema del ser demoniaco para "canjear" la salvación del cuerpo por el alma de los vacunados. Se trata, pues de una narrativa conspirativa religiosa tradicional en la que se enfrentan eternamente el bien y el mal por nuestras almas. Hay, por tanto, un entimema.

-El contenido elidido de este entimema se resuelve en la conocida tradición cristiana, según la cual, el demonio tienta a las personas al ofrecerles algo preciado a cambio de sus almas. La trampa diabólica se orquesta porque el producto deseado (la vacuna) es obtenido a través del pecado.

-Si se incluye en el entimema la información elidida, el silogismo sería:

ESTANDARIZAGIÓN DEL ARGUMENTO CON INCLUSIÓN DEL ENTIMEMA

1. Hay un ser demoniaco.

2. Hay una pandemia.

\section{El ser demoniaco nos tienta con la vacuna.}

4. La vacuna se obtendrá de fetos abortados.

5. (de 1 a 4): La vacuna es pecaminosa.

6. La vacuna es investigada por la ciencia.

7. (de 5 y 6): La ciencia es la ejecutora de los intereses demoniacos.

8. (de 2, 5 y 7): El demonio está presente en la pandemia y la vacuna no es buena para la humanidad.

-Pese a que la narrativa presente en el silogismo tiene coherencia interna, sigue siendo errónea en función de su semántica, pues presupone la existencia de un ser no humano ni físico que puede interactuar con los humanos para arrebatarle algo no físico (el alma).

\section{Conclusiones}

-El pensamiento conspirativo contiene falacias y entimemas.

-En tiempos de pandemia, las personas tienden a argumentar desde la falacia, el sesgo y el entimema en lugar de utilizar convenientemente la lógica y los conocimientos científicos.

-Es importante conocer la estructura lógica del pensamiento conspirativo para poder buscar las formas viables de corregirlo.

-El esfuerzo por conocer la lógica del pensamiento conspirativo y de las falacias, sesgos y entimemas que lo contienen contribuyen al desarrollo del pensamiento crítico.

\section{Referencias}

Bordes, M. (2017). Las trampas de Circe: falacias lógicas y argumentación informal. Cátedra.

Dimara, E., Franconeri, S., Plaisant, C., Bezerianos, A., \& Dragicevic, P. (2020). Una taxonomía basada en tareas de sesgos cognitivos para la visualización de información. IEEE Transactions on Visualization and Computer Graphics, 26(2), 1413-1432. https://doi.org/10.1109 / TVCG.2018.2872577 
García, R. (s.f.). Diccionario de falacias. http://www.usoderazon.com/conten/arca/ARCAPDFCOMPLETO. pdf

Hernáiz, H. A. (2009). Teorías de la conspiración, Entre la magia, el sentido común y la ciencia. Prisma social.

Kahneman, D. (2016). Pensar rápido, pensar despacio. Debolsillo.

Matute, H. (2019). Nuestra mente nos engaña, sesgos y errores cognitivos que todos cometemos. Shackleton Books, S.L.

Pérez, H. (2009). Teorías de la conspiración: Entre la Magia, el Sentido Común y la Ciencia. Prismasocial - Revista de Ciencias Sociales,

http://www.isdfundacion.org/publicaciones/revista/pdf/n2 11.pdf

Shermer, M. (2009). Por qué creemos en cosas raras. Alba.

Tversky, A., \& Kahneman, D. (1975). Judgment under uncertainty: Heuristics and biases, in Utility, probability, and human decisión making. Springer, 1975, pp. 141-162.

La República (28 de agosto de 2020). Congresista Orlando Arapa desliza sin pruebas que "avionetas estarían esparciendo el coronavirus en Puno". La República. https://larepublica.pe/politica/2020/08/28/congresista-de-punoorlando-arapa-avionetas-estarian-esparciendo-el-coronavirusaudio-Irsd/

La República (19 de abril de 2020). La insólita teoría de Marat Safin sobre el coronavirus: "Todo es para la implantación del chip". La República. https://larepublica.pe/deportes/2020/04/19/maratsafin-y-su-insolita-teoria-sobre-el-coronavirus-todo-es-para-laimplantacion-de-chips-y-bill-gates-lo-sabe-tenis/

Redacción y agencias (15 de junio de 2020). El cardenal Cañizares advierte que la vacuna del coronavirus se hace con "fetos abortados". La Vanguardiahttps://www.lavanguardia.com/vida/20200615/481785354513/car denal-canizares-valencia-vacuna-fetos-abortadoscoronavirus.html 